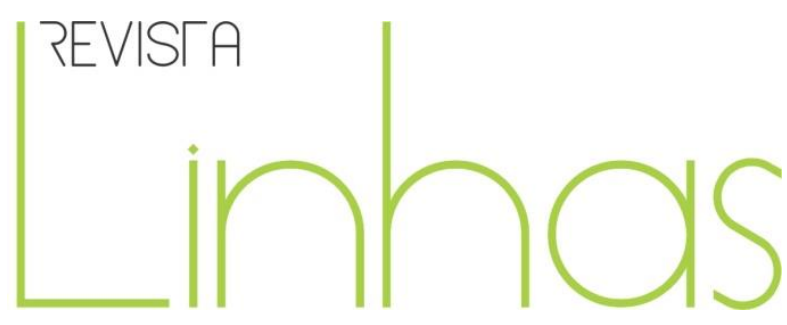

\title{
A educação da pessoa com deficiência visual: marcos históricos e políticos da formação e atuação docente
}

\section{Resumo}

A diversidade humana tem desafiado a educação contemporânea à convivência com as diferenças, em particular com as pessoas deficientes visuais, protagonistas do presente estudo, que propõe analisar o Plano Nacional de Educação, Lei n 13.005, Meta 4, e em específico as estratégias que tratam da formação e atuação docente em articulação com a atual Política Nacional de Educação Especial na Perspectiva da Educação Inclusiva. Um panorama histórico e político do atendimento educacional a deficientes visuais, de meados do século XIX a início do XXI, será delineado para uma compreensão dos atuais desafios anunciados pelas políticas públicas, que consideram a articulação precípua entre a formação de professores e as práticas pedagógicas no que tange o Atendimento Educacional Especializado (AEE). Portanto, constitui-se objetivo deste estudo problematizar a educação da pessoa com deficiência visual nas discussões da formação de professores. Para tanto, contamos com as contribuições de autores como: Marcos José Mazzota e Elcie Masini, que elucidam os principais fatos e momentos históricos, assim como a evolução do atendimento educacional ao deficiente visual, bem como possibilitam discutir as ações governamentais no âmbito da formação e atuação docente. A metodologia da pesquisa segue a abordagem bibliográfica, que permite adensar analiticamente a problemática da formação de professores e a questão das práticas pedagógicas. Mas, todas essas recomendações legais e educacionais aqui exploradas, revelam a necessidade constante de revisitar a realidade da educação brasileira na busca de superação das dificuldades impostas pela deficiência visual na proposição de uma ação contínua.

Palavras-chave: Educação. Deficientes Visuais. Professores. Formação.
Rogério Sousa Pires Instituto Federal Catarinense IFC - Campus Rio do Sul/SC Brasil rogersp@ifc-riodosul.edu.br

\section{Reginaldo Leandro Plácido} Instituto Federal Catarinense IFC - Campus Araquari/SC Brasil reginaldo.placido@ifcaraquari.edu.br

\footnotetext{
Para citar este artigo:

PIRES, Rogério Sousa; PLÁCIDO, Reginaldo Leandro. A educação da pessoa com deficiência visual: marcos históricos e políticos da formação e atuação docente. Revista Linhas. Florianópolis, v. 19, n. 39, p. 30-54, jan./abr. 2018.
} 


\title{
The education of the person with visual deficiency: historical and political frameworks of training and teaching activities
}

\begin{abstract}
Human diversity has challenged contemporary education to coexist with the differences, particularly with visually impaired people, protagonists of the present study, who proposes to analyze the National Education Plan, Law 13.005, Goal 4, and in particular the strategies that deal with of the formation and teaching performance in articulation with the current National Policy of Special Education in the Perspective of Inclusive Education. A historical and political overview of educational care for the visually impaired, from the mid-nineteenth century to the beginning of the twenty-first century, will be delineated for an understanding of the current challenges announced by public policies, which consider the primary articulation between teacher training and pedagogical practices in which covers the Specialized Educational Assistance (AEE). Therefore, it is the objective of this study to problematize the education of the visually impaired person in the discussions of teacher training. To that end, we count on the contributions of authors such as Marcos José Mazzota and Elcie Masini, who elucidate the main facts and historical moments, as well as the evolution of educational assistance to the visually impaired, as well as make it possible to discuss governmental actions in the field of training and teaching performance. The methodology of the research follows the bibliographical approach, which allows analyzing analytically the problem of teacher training and the question of pedagogical practices. However, all these legal and educational recommendations explored here reveal the constant need to revisit the reality of Brazilian education in order to overcome the difficulties imposed by visual impairment in proposing a continuous action.
\end{abstract}

Keywords: Education. Visually Impaired. Teachers. Formation. 


\section{Introdução}

O presente estudo propõe analisar o Plano Nacional de Educação, Lei nº 13.005 (BRASIL. Presidência da República, 2014), Meta 4, e em específico as estratégias que tratam da formação e atuação docente em articulação com a atual Política Nacional de Educação Especial na Perspectiva da Educação Inclusiva. E a principal protagonista deste estudo, a pessoa com deficiência visual é destacada com a caracterização da educação especial como parte do seu mundo vivido.

Fatos históricos e políticos demonstram o percurso da Educação Especial até chegar a atual configuração política com o Atendimento Educacional Especializado $(\mathrm{AEE})$ à pessoa com deficiência matriculada e frequentadora das escolas públicas. Para tanto, contamos com as contribuições de autores como: Marcos José Mazzota (2001) e Elcie Masini (1994, 1997, 2007 e 2013), que abordam respectivamente: os principais fatos e momentos histórico-políticos do atendimento educacional à pessoa com deficiência nos contextos mundial e brasileiro; orientações para educadores nas relações de educabilidade com pessoas deficientes visuais. É a partir destas referências, juntamente com os textos oficiais e legais, e outros autores, que se intenciona explicitar e discutir as ideologias presentes nas políticas púbicas e nas ações governamentais no âmbito da formação e atuação docente para a educação do aluno deficiente visual no contexto da diversidade humana.

A natureza mesma da educação especial, enquanto fenômeno e atividade humana, nos remete a um processo complexo que vai da segregação institucional ao movimento pela inclusão. E Mazzotta, ao discutir a complexidade da educação escolar, defende uma

Abordagem dinâmica (unidade entre comum e especial) como aquela que, baseada no princípio da não segregação, possibilita a melhor compreensão da relação entre o educando e a educação escolar e comporta a organização de situações de ensino-aprendizagem mais condizentes com as necessidades educacionais a atender. (MAZZOTA, 2001, p. 01) 
A unidade é fundamental para que as escolas comuns de qualidade especial celebrem a diversidade, se preocupem com a humanidade, e coloquem como centro de suas preocupações o ser humano, levando em consideração a sua condição de sujeito complexo. Portanto, faz-se necessário "ensinar a condição humana” e saber conviver com ela.

$\mathrm{Na}$ história da educação, a lógica excludente impedia o vislumbre de uma aceitação/inclusão das pessoas com deficiência, como afirma Mazzotta (2001a),

O atendimento educacional dos portadores de deficiência, (...) até o século XVIII, as noções a respeito da deficiência eram basicamente ligadas a misticismo e ocultismo, não havendo base científica para o desenvolvimento de noções realísticas. O conceito de diferenças individuais não era compreendido ou avaliado (...) a falta de conhecimento sobre as deficiências em muito contribuiu para que as pessoas portadoras de deficiência, por 'serem diferentes' fossem marginalizadas, ignoradas. (MAZZOTTA, 2001a, p. 16)

Do exposto, o que nos chama a atenção é o risco das significações sociais que sedimentam sob o humano, impedimentos para o seu desenvolvimento, cuja tônica está na subtração das funções perdidas em decorrência da deficiência. Mas uma nova maneira de compreender a pessoa com deficiência visual foi posicionada por Lev Vigotski (1997), ao afirmar de um lado a eficiência do potencial humano em contraposição à ênfase na deficiência, privilegiando as características da pessoa, ao dizer que,

A cegueira, ao criar uma formação peculiar de personalidade, reanima novas fontes, muda as direções normais do funcionamento e, de uma forma criativa e orgânica, refaz e forma o psiquismo da pessoa. Portanto, a cegueira não é somente um defeito, uma debilidade, senão também em certo sentido uma fonte de manifestação das capacidades, uma força. (Por estanho que seja, semelhante a um paradoxo). (VIGOTSKI, 1997, p. 99)

A educação é chamada a tomar uma posição de ruptura do enfoque tradicional, que focaliza o defeito, a falha, o estigma, a deficiência, e direcionar sua atenção para novas fontes que configuram outra ordem - a do desenvolvimento cultural - a 
compensação da deficiência. No caso da criança deficiente, o defeito exerce uma dupla valência no desenvolvimento humano:

Por um lado, ele é uma deficiência, e atua diretamente como tal, produzindo falhas, obstáculos, dificuldades na adaptação da criança. Por outro lado, exatamente porque o defeito produz obstáculos e dificuldades no desenvolvimento e rompe o equilíbrio normal, ele serve de estímulo ao desenvolvimento de caminhos alternativos de adaptação, indiretos, os quais substituem ou superpõem funções que buscam compensar a deficiência, e conduzir todo o sistema de equilíbrio rompido a uma nova ordem. (VIGOTSKI, 2011, p. 869)

Assim, ao trazer para o âmbito da pesquisa as caracteristicas da criança cega e não sua deficiência contamos com as contribuições de Vigotski, que na década de 1920 em Moscou, estudou os fundamentos da deficiência no Laboratório de Psicologia para Crianças Deficientes, com um olhar direcionado para o potencial humano de desenvolver e ampliar-se pela compensação da deficiencia.

Os sentidos são importantes na exploração sensorial, mas não podemos nos reduzir ao pensamento comum que considera a percepção tátil ou a remanescência de outros sentidos, a forma de compensação do deficiente visual, como processo meramente orgânico, ancorado no treinamento sensorial, cognitivo, comportamental. É a linguagem, como utilização da experiência social, o instrumento de compensação da cegueira. Deste modo,

A aprendizagem humana se dá com base na convivência social, na apropriação das atividades historicamente engendradas pelos homens, pela internalização dos significados sociais. Assim, o homem conhece o mundo pela atividade simbolizadora nas relações sociais. Toda atividade humana é constituída de significados que são mediados, de um homem para o outro, pela linguagem, que é o sistema simbólico básico de comunicação de todos os grupos humanos. Entre as várias linguagens que representam o real, a palavra é ímpar. (CAIADO, 2003, p. 39)

Uma compensação orientada para os aspectos históricos, culturais e sociais da vida concreta humana, que ocorre por meio da linguagem, da medicação social (processos compensatórios guiados pelas leis sociais que apontam para a superação das 
dificuldades). A linguagem, os signos, o outro, são funções mentais superiores que permitem ao sujeito deficiente o acesso ao desenvolvimento, a compensação das dificuldades e, possibilita a inserção dele nas práticas socioculturais, transformando-as. Vigotski (1997) entende a deficiência como uma construção social, sendo o sujeito considerado na sua singularidade. Acredita que não se deve negar a deficiência, mas sim buscar caminhos para enfrentá-la, com a utilização, por exemplo, do sistema Braille e das tecnologias assistivas.

A aceitação das diferenças individuais, a valorização de cada pessoa, a convivência dentro da diversidade humana e a aprendizagem por meio da cooperação são princípios defendidos pela nova ordem da Educação Especial sob o enfoque da Educação Inclusiva. Saber conviver com a diversidade humana representa aceitar as diferenças, em qualquer lugar e a escola, na nossa sociedade, é um dos espaços mais importantes para o acesso ao conhecimento e aos bens culturais.

\section{Dos marcos históricos e políticos à atual configuração para a formação e atuação docente}

No contexto brasileiro, os primeiros trabalhos para a educação do cego e de pessoas com baixa visão começaram de forma mais sistematizada em meados do século XIX, ano de 1854 quando foi criado no Rio de Janeiro o Imperial Instituto dos Meninos Cegos, hoje Instituto Benjamin Constant. Este instituto público federal atendia e ainda atende crianças, adolescentes e adultos, nas modalidades da educação básica, reabilitação ${ }^{1}$ e capacitação profissional.

Como iniciativa oficial do governo concretizada por D. Pedro II, através do Decreto Imperial $n^{\circ} 1428$, fundou-se o primeiro educandário para alunos cegos na América Latina, que constitui o marco inicial da Educação Especial no Brasil.

\footnotetext{
1 Entende-se por Reabilitação o processo que fornece à pessoa com deficiência visual informações necessárias para favorecerem seu desenvolvimento pessoal e funcional, propiciando condições de autonomia e independência, e proporcionando a inclusão social. Possibilita às pessoas com deficiência visual um nível funcional adequado do ponto de vista físico, psíquico e social. (Cf. FUNDAÇÃo DORINA NOWIIL PARA CEGOS, 2016)
} 
A fundação do Imperial Instituto deveu-se, em grande parte, a um cego brasileiro, José Álvares de Azevedo, que estudara no Instituto dos Jovens Cegos de Paris, fundado por Valentin Haüy no século XVIII. Por ter obtido muito sucesso na educação de Adélia Sigaud, filha do Dr. José F. Xavier Sigaud, médico da família imperial, José Álvares de Azevedo despertou a atenção e o interesse do Ministro do Império, Conselheiro Couto Ferraz. Sob a influência de Couto Ferraz, D. Pedro II criou tal Instituto, que foi inaugurado no dia 17 de setembro de 1854, cinco dias após sua criação. Para dirigi-lo, foi nomeado o Dr. Xavier Sigaud (...)

Em 24 de janeiro de 1891, pelo Decreto $n^{\circ} 1320$, a escola passou a denominar-se Instituto Benjamin Constant (IBC), em homenagem a seu ilustre e atuante ex-professor de Matemática e ex-diretor, Benjamin Constant Botelho de Magalhães. (MAZZOTTA, 2001a, p. 28)

Outra fase importante no processo educacional das pessoas com deficiência visual foi a oficialização, em 1946, do Curso Ginasial do IBC através da Portaria $n^{\circ} 385$, de 8 de junho, que possibilitou o acesso dos alunos à educação, equiparada ao ginásio de ensino comum. Também no mesmo ano, na cidade de São Paulo, Dorina de Gouvêa ${ }^{2}$ junto com um grupo de amigas, deu início às atividades da Fundação para o Livro do Cego no Brasil, "tendo como finalidade a integração do deficiente visual na comunidade como pessoa auto-suficiente e produtiva" (MAZZOTTA, 2001a, p. 35) com objetivo inicial de produzir e distribuir livros em Braille, e depois passou a atuar nas áreas de educação e reabilitação de pessoas com deficiência visual.

Na década de 1950 foi realizada, ainda que em caráter experimental, no Instituto Caetano de Campos, "a primeira sala de recursos para deficientes visuais estudarem em classes comuns" (MASINI, 2013, p. 50), que recebeu suporte da Fundação para o Livro do Cego no Brasil e, foi a "primeira instituição a capacitar professores especializados para a atuação em escolas públicas" (Idem).

Em 1958, sob o Decreto $n^{\circ} 44.236$, de $1^{\circ}$ de agosto, criou-se a Campanha Nacional de Educação e Reabilitação de Deficientes da Visão inspirada na campanha iniciada pelo

\footnotetext{
${ }^{2}$ Foi a primeira aluna cega a frequentar um curso regular na Escola Normal Caetano de Campos, tendo conseguido, posteriormente, a integração de outra menina cega num curso regular da mesma escola. Colaborou para a elaboração da lei de integração escolar, regulamentada em 1956. De 1961 a 1973 dirigiu a Campanha Nacional de Educação de Cegos do Ministério da Educação e Cultura (MEC). Em sua gestão foram criados os serviços de educação de cegos em todas as Unidades da Federação. (Cf. FUNDAÇÃO DORINA NOWILL PARA CEGOS, 2016)
} 
Instituto Benjamin Constant, posteriormente chamada de Campanha Nacional de Educação de Cegos - CNEC, vinculada diretamente ao Gabinete do Ministro da Educação.

Com a criação da CNEC e as atividades então desenvolvidas, como: treinamento e especialização de professores e técnicos no campo da educação e reabilitação de deficientes visuais, incentivo, produção e manutenção de facilidades educacionais, incluindo equipamentos, livros, auxílios ópticos e material para leitura e escrita, além da assistência técnica e financeira aos serviços de educação especial e reabilitação, o Ministério da Educação e Cultura procurou através dessa Campanha oferecer maiores oportunidades de atendimento educacional aos deficientes da visão. (LEMOS apud MAZZOTTA, 2001a, p. 51)

Os desdobramentos da campanha contribuíram para a criação de cursos de formação docente, como foram os desenvolvidos no estado de São Paulo nas universidades e faculdades, buscando expandir o ideal do ensino integrado, tendo como norte o princípio da normalização, cujas práticas de integração visavam "oferecer às pessoas com deficiências condições de vida diária semelhantes aos que não tinham deficiência" (MASINI, 2013, p. 51). A integração fundamentava-se no modelo médico de deficiência, “cujo objetivo era a adaptação da pessoa com deficiência às exigências ou necessidades da sociedade como um todo" (Idem).

Verifica-se que a formação de professores para a Educação Especial tomou proporções de nível nacional a partir da criação, em 1973, do Centro Nacional de Educação Especial (CENESP), órgão vinculado ao Ministério da Educação que instaurou o Plano Nacional de Educação Especial, tendo como uma das frentes prioritárias a capacitação de recursos humanos para atuar junto aos alunos com deficiência. O mesmo Centro também implementou o projeto Reformulação de Currículos para Educação Especial, que de acordo com Soares e Carvalho (2012, p. 28), era "destinado à orientação do trabalho pedagógico específico para as deficiências intelectual, visual, auditiva e para os superdotados."

Segundo Mazzotta (2001a), logo após a criação do CENESP, extinguiu-se a Campanha Nacional de Educação de Cegos bem como a Campanha Nacional de Educação e Reabilitação de Deficientes Mentais, e sua finalidade consta em Regimento próprio, que dispõe no Artigo $2^{\circ}$ : 
O CENESP tem por finalidade planejar, coordenar e promover o desenvolvimento da Educação Especial no período pré-escolar, nos ensinos de $1^{\circ}$ e $2^{\circ}$ graus, superior e supletivo para os deficientes da visão, da audição, mentais, físicos, portadores de deficiências múltiplas, educandos com problemas de conduta e os superdotados, visando à sua participação progressiva na comunidade, obedecendo aos princípios doutrinários, políticos e científicos que orientam a Educação Especial. (MAZZOTA, 2001a p. 56)

$\mathrm{Na}$ Proposta Curricular para Deficientes Visuais do CENESP/MEC, de 1976, elaborada pela Universidade do Estado do Rio de Janeiro (UERJ), como fruto de um trabalho em equipe de professores especialistas, enfatizou-se “... a necessidade de capacidade prévia do deficiente visual para as atividades escolares comuns" (MASINI, 1994, p. 56), o que coloca a tônica na ausência da visão e não naquilo que poderia ser potencializado na maneira própria de perceber do aluno. E isso é reiterado por Masini, que ao analisar a proposta, conclui que

O deficiente visual não é considerado na sua totalidade, como um indivíduo com características próprias, das quais uma delas é a deficiência visual. A programação, ao contrário disso, focaliza-o como indivíduo deficiente e não leva em conta sua maneira própria de perceber. (MASINI, 1994, p. 56)

Dentre as instituições de ensino superior que começaram a oferecer cursos de habilitação docente na área da Educação Especial, destacam-se na década de 70: Faculdade de Educação da Unesp, em Marília, Faculdade do Carmo, em Santos; e na década de 80: Universidade de São Paulo e Faculdade de Educação do Paraná.

Sob a égide do paradigma integracionista caminha-se da segregação para a integração, que teve início com a criação das primeiras escolas especiais que apesar de segregacionistas, prestaram relevantes serviços em seu contexto histórico. Com o tempo novas configurações sociais sugiram e no seu bojo, "as demandas por uma educação integrada do aluno com deficiência visual” (MASINI, 2013, p. 50), que se consolidou na década de 1980. 
Novas conquistas surgiram no panorama mundial com o movimento internacional de pessoas com deficiência em 1979, que influenciaram na criação das recomendações de organismos internacionais sobre a Educação Especial (CARVALHO, 2002), como as instituídas pela Organização das Nações Unidas (ONU) que declarou em 1981 como o Ano e a Década da Pessoa Portadora de Deficiência. Trata-se de um marco que evidencia o protagonismo das pessoas com deficiência, requerendo proximidade e controle das ações que lhe diziam respeito. Neste sentindo,

Os movimentos sociais das pessoas com deficiência, na intenção de estimular o processo participativo e garantir a interlocução com o Estado, optaram por formalizar entidades jurídicas, "profissionalizando" serviços e lutas. Desta forma, constituindo uma identidade social e política, explicitaram as demandas e estratégias - ora de enfrentamento, ora de negociação - na construção do processo democrático e na busca do respeito às diferenças e da igualdade de oportunidades. A grande conquista do período foi, certamente, a potencialização social e política dessas pessoas, como retrata militante de movimentos sociais de cegos, com histórico de titular no Conselho Nacional dos Direitos da Pessoa com Deficiência: "O Governo só faz se a sociedade civil empurrar, cobrar, propor, fiscalizar. Os movimentos sociais são molas propulsoras das políticas públicas". (CARVALHO FILHO e FERREIRA, 2013, p. 106)

Na esteira do movimento pela inclusão, Carvalho (2002) afirma que na década de 1990, surgem a Declaração Mundial de Educação para Todos de Joimtien (1990) e a Declaração de Salamanca (1994). Esta última assevera que o princípio da inclusão consiste no "reconhecimento da necessidade de si caminhar rumo à 'escola para todos' - um lugar que inclua todos os alunos, celebre a diferença, apoie a aprendizagem e responda às necessidades individuais" (SASSAKI, 2003, p. 119-120). O desafio para uma escola inclusiva é o de desenvolver uma pedagogia centrada no aluno, uma pedagogia capaz de educar com sucesso todos os alunos, incluindo aqueles com deficiências (MACHADO, 2005, p. 131). O autor afirma ainda, que "o princípio fundamental da escola inclusiva é o de que todas as crianças devem aprender juntas, sempre que possível, não importam quais dificuldades ou diferenças elas podem ter" (MACHADO, 2005, p. 133).

Os laços de pertencimento social e o enfrentamento de adversidades se construíram através de fazeres propositivos e coletivos, ganhando nova dimensão e 
possibilidade de eficácia quando se articularam em redes locais e/ou universais (CARVALHO FILHO e FERREIRA, 2013, p. 113). E no âmbito nacional, historicamente, a luta dos cegos para uma educação de qualidade com a criação de institutos, fundações e escolas, assim como a preocupação com a formação docente revela a atuação política de pessoas com deficiências e outros agentes sociais na defesa do princípio da inclusão escolar, evidenciando assim, o protagonismo desse público da Educação Especial.

O Movimento Diretas Já, em 1983, a nova ordem instaurada com o processo de redemocratização e a proclamação da Constituição Brasileira de 1988, trazem um novo olhar para a Educação Especial, que a partir da década de 1990 intensifica-se com o crescente movimento pela inclusão. E isso traz desdobramentos importantes para a educação brasileira, com algumas medidas oficiais tomadas por órgãos governamentais, no intuito de oferecer suporte para professores, como por exemplo, as políticas de formação de professores após a abertura política, especificamente a partir da década de 1990 com a promulgação da Política Nacional de Educação Especial (1994).

Em 1996, um importante passo foi dado na contemplação das pessoas com deficiência, com políticas sociais e educacionais, como foi com a promulgação da Lei $n^{\circ}$ 9.394 - Lei de Diretrizes e Bases da Educação Nacional (LDBEN), que pela primeira vez dedica um capítulo inteiro ao tema da Educação Especial, que tem no Título V - Dos níveis e modalidades de educação e ensino, do Capítulo V - Da educação especial, Art. 58, a seguinte definição: “Entende-se por educação especial, para os efeitos desta Lei, a modalidade de educação escolar, oferecida preferencialmente na rede regular de ensino, para educandos portadores de necessidades especiais" (BRASIL. Presidência da República, 1996). Em 2013, o Art. 58, foi alterado pela Lei $n^{\circ} 12.796$, com a seguinte redação: "Entende-se por educação especial, para os efeitos desta Lei, a modalidade de educação escolar oferecida preferencialmente na rede regular de ensino, para educandos com deficiência, transtornos globais do desenvolvimento e altas habilidades ou superdotação" (BRASIL. Presidência da República, 2013a).

É inegável que o tema ganhou destaque, se comparado com a apresentação nas duas leis anteriores. Na Lei 4.024/61, título X: "Da Educação de excepcionais", os art. 88 e 89 indicam que "a educação de excepcionais deve, no que for possível, enquadrar-se no sistema geral de 
educação". Na Lei 5.692/71, o art. $9^{\circ}$ do capítulo I, que trata das disposições comuns ao ensino de $1^{\circ}$ e $2^{\circ}$ grau, afirma que os alunos que apresentam "deficiências físicas e mentais" deverão receber tratamento especial no ensino de $1^{\circ}$ e $2^{\circ}$ grau, conforme as normas fixadas pelos Conselhos de Educação. (CAIADO, 2003, p. 22)

Da preocupação para a formação e atuação docente junto às pessoas com deficiência, foi lançada a Série Atualidades Pedagógicas (BRUNO, MOTA, 2001), que nos três fascículos dedicados a deficiência visual, traz primeiramente a caracterização da deficiência visual, seguida do processo de educação precoce da educação infantil ao ensino pré-escolar. No segundo fascículo, aborda a escolarização do aluno com deficiência visual, com destaque para a alfabetização, o Sistema Braille, os recursos didáticos e adaptações curriculares. No último fascículo, apresenta as complementações curriculares específicas (Sorobã, Atividades da Vida Diária, Orientação e Mobilidade, Escrita Cursiva), o processo de socialização e a profissionalização da pessoa com deficiência visual, e reabilitação.

Em 2001, é aprovado o Plano Nacional de Educação, Lei $n^{\circ} 10.172$ (BRASIL. Presidência da República, 2001), que no âmbito da Educação destaca a importância do papel da sociedade civil em assumir as diretrizes, objetivos e metas da Educação Especial como responsabilidade de garantir o direito à educação, pelo acesso, permanência e indicadores de qualidade do ensino a esse alunado. Preocupação revisitada após a vigência do PNE, com tramitação na Câmara e Senado Federal do Projeto de Lei por mais de três anos, sendo sancionado pela presidente da República como Lei n 13.005, de 25 de junho de 2014.

Dentre suas metas e estratégias, a Meta 4, merece atenção, pois trata da área da Educação Especial, e destaca a necessidade de:

Universalizar, para a população de 4 (quatro) a 17 (dezessete) anos com deficiência, transtornos globais do desenvolvimento e altas habilidades ou superdotação, o acesso à educação básica e ao atendimento educacional especializado, preferencialmente na rede regular de ensino, com a garantia de sistema educacional inclusivo, de salas de recursos multifuncionais, classes, escolas ou serviços especializados, públicos ou conveniados. 
Estratégia 4.13: apoiar a ampliação das equipes de profissionais da educação para atender à demanda do processo de escolarização dos (das) estudantes com deficiência, transtornos globais do desenvolvimento e altas habilidades ou superdotação, garantindo a oferta de professores (as) do atendimento educacional especializado, profissionais de apoio ou auxiliares, tradutores (as) e intérpretes de Libras, guias-intérpretes para surdos-cegos, professores de Libras, prioritariamente surdos, e professores bilíngues;

Estratégia 4.16: incentivar a inclusão nos cursos de licenciatura e nos demais cursos de formação para profissionais da educação, inclusive em nível de pós-graduação, observado o disposto no caput do art. 207 da Constituição Federal, dos referenciais teóricos, das teorias de aprendizagem e dos processos de ensino-aprendizagem relacionados ao atendimento educacional de alunos com deficiência, transtornos globais do desenvolvimento e altas habilidades ou superdotação;

Estratégia 4.18: promover parcerias com instituições comunitárias, confessionais ou filantrópicas sem fins lucrativos, conveniadas com o poder público, visando a ampliar a oferta de formação continuada e a produção de material didático acessível, assim como os serviços de acessibilidade necessários ao pleno acesso, participação e aprendizagem dos estudantes com deficiência, transtornos globais do desenvolvimento e altas habilidades ou superdotação matriculados na rede pública de ensino. (BRASIL. Presidência da República, 2014)

Nas estratégias destacadas aparece uma preocupação recorrente sobre a formação e atuação docente, que levantam o seguinte questionamento: o que transformar quanto à deficiência visual? A questão levantada desdobra-se para o espaço escolar, ao inquerir se as escolas estão abertas às diferenças - ao ensino inclusivo. E para que as escolas mudem - que ações implementar? Qual postura docente assumir frente à pessoa com deficiência visual na classe regular?

Com o intuito de ampliar as equipes de profissionais, incluir referenciais teóricos específicos nos cursos de formação de professor e estabelecer parcerias para a ampliação da oferta de formação continuada, algumas medidas precedentes que convergiram para a Lei $n^{\circ} 13.005$ revelam uma preocupação já manifesta com a implementação de políticas públicas direcionadas à inclusão escolar.

Em 2007 o lançamento do Plano de Desenvolvimento da Educação - PDE, pactuado pela Agenda Social, tem dentre seus eixos, a formação docente para a Educação Especial, e a implementação das salas de recursos multifuncionais, que no ano 
seguinte seriam instaladas em todos os entes federados (Estados, Distrito Federal e Municípios) (BRASIL. Ministério da Educação, 2007).

Em 2008, a Secretaria de Educação Especial (SEESP/MEC), lança o documento “Política Nacional de Educação Especial na Perspectiva da Educação Inclusiva”, com a seguinte orientação, dentre outras:

A educação especial direciona suas ações para o atendimento às especificidades desses alunos no processo educacional e, no âmbito de uma atuação mais ampla na escola, orienta a organização de redes de apoio, a formação continuada, a identificação de recursos, serviços e o desenvolvimento de práticas colaborativas. (BRASIL. Ministério da Educação, 2008, p. 15)

Da análise dos marcos históricos e normativos, e pelo diagnóstico feito pela comissão do grupo de trabalho que elaborou o documento com as novas diretrizes para a Educação Especial, tem-se a seguinte definição:

A educação especial é uma modalidade de ensino que perpassa todos os níveis, etapas e modalidades, realiza o atendimento educacional especializado, disponibiliza os serviços e recursos próprios desse atendimento e orienta os alunos e seus professores quanto a sua utilização nas turmas comuns do ensino regular. (BRASIL. Ministério da Educação, 2008, p. 15)

A partir de então, fica definido que o Atendimento Educacional Especializado $(A E E)$, ofertado pelas escolas públicas estaduais e municipais, é complementar ao ensino da sala regular. Em consonância ao Decreto $n^{\circ}$ 6.571, de 17 de setembro de 2008, a Política Nacional dispõe sobre o AEE em seu artigo $1^{\circ}$, e parágrafos subsequentes:

Art. $1^{\circ}$ A União prestará apoio técnico e financeiro aos sistemas públicos de ensino dos Estados, do Distrito Federal e dos Municípios, na forma deste Decreto, com a finalidade de ampliar a oferta do atendimento educacional especializado aos alunos com deficiência, transtornos globais do desenvolvimento e altas habilidades ou superdotação, matriculados na rede pública de ensino regular. 
$\S 1^{\circ}$ Considera-se atendimento educacional especializado o conjunto de atividades, recursos de acessibilidade e pedagógicos organizados institucionalmente, prestado de forma complementar ou suplementar à formação dos alunos no ensino regular.

$\S 2^{\circ} \mathrm{O}$ atendimento educacional especializado deve integrar a proposta pedagógica da escola, envolver a participação da família e ser realizado em articulação com as demais políticas públicas. (BRASIL. Ministério da Educação. Secretaria de Educação Especial, 2010, p. 28)

O Ministério da Educação com a atual política de educação inclusiva que norteia a Educação Especial, de forma transversal e complementar ao Ensino Regular, instituiu as diretrizes e ações dos serviços de Atendimento Educacional Especializado, "oferecidos aos alunos com deficiência visando a complementação da sua formação e não mais a substituição do ensino regular" (BRASIL. Secretaria de Educação Especial; BRASIL. Secretaria de Educação a Distância, 2007, p. 05).

Com o intuito de responder às necessidades educacionais especiais, garantindo um dos objetivos da atual política da Educação Especial: formação de professores para o Atendimento Educacional Especializado e demais profissionais da educação para a inclusão escolar, a União, buscando aperfeiçoar os professores da rede pública de educação organiza um curso em parceira com as Secretaria de Educação Especial e a Secretaria de Educação a Distância. O curso tem carga horária total de 180 horas, das quais 34 horas são destinadas ao Atendimento Especializado em Deficiência Visual. Tratase de um projeto de formação continuada mediado pelo programa "Educação Inclusiva: direito à diversidade".

O curso desenvolvido enfatiza as áreas de deficiência física, auditiva, visual e intelectual, e possui uma estrutura para:

- trazer o contexto escolar dos professores para o foco da discussão dos novos referenciais para a inclusão dos alunos;

- introduzir conhecimentos que possam fundamentar os professores na reorientação das suas práticas de Atendimento Educacional Especializado;

- desenvolver aprendizagem participativa e colaborativa necessária para que possam ocorrer mudanças no Atendimento Educacional Especializado. (BRASIL. Secretaria de Educação Especial; BRASIL. Secretaria de Educação a Distância, 2007, p. 05) 
O curso orientou-se pela reorganização dos sistemas de ensino de modo que o AEE através do Programa de Implantação de Salas de Recursos Multifuncionais pudesse atender o alunado dessa modalidade de ensino no contra turno ao frequentado na sala comum e, também, possibilitar ao professor revisitar suas práticas sob o enfoque dos novos referenciais pedagógicos da inclusão.

Portanto, por meio da Resolução $n^{\circ} 4$ CNE/CEB 2009, instituída pelo Conselho Nacional de Educação, ficaram estabelecidas as Diretrizes Operacionais para o Atendimento Educacional Especializado na Educação Básica, e de acordo com o Art. $5^{\circ}$ :

\begin{abstract}
O AEE é realizado, prioritariamente, nas salas de recursos multifuncionais da própria escola ou em outra de ensino regular, no turno inverso da escolarização, não sendo substitutivo às classes comuns, podendo ser realizado, em centro de atendimento educacional especializado de instituição especializada da rede pública ou de instituição especializada comunitárias, confessionais ou filantrópicas sem fins lucrativos, conveniadas com a secretaria de educação ou órgão equivalente dos estados, do Distrito Federal ou dos municípios. (BRASIL. Presidência da República, 2013a, p. 05-06)
\end{abstract}

Dos volumes que compõem o material formativo da coleção do AEE, o dedicado aos alunos com deficiência visual (BRASIL. Ministério da Educação, 2007), de acordo com Soares e Carvalho (2012), não oferece nesta atual proposta nenhuma novidade, pois é direcionada sob o mesmo esquema da anterior - Série Atualidades Pedagógicas (BRUNO, MOTA, 2001), pautando-se também pela descrição da inclusão escolar de alunos cegos e com baixa visão, seguida da descrição da funcionalidade da visão na utilização de recursos ópticos e não ópticos. Na alfabetização e aprendizagem, aborda a comunicação e relacionamento, o sistema Braille, atividades e avaliação, e recursos didáticos. Por último, traz a informática com seus recursos tecnológicos assistivos. Em suma, "a publicação prende-se à descrição dos aspectos técnicos e uso de adaptação, não abordando (...) como todo esse material pode ser utilizado no trabalho pedagógico a ser utilizado nas salas de AEE"'. (SOARES; CARVALHO, p. 50).

Apesar da falta de adensamento nas orientações pedagógicas para educadores, as publicações oficiais além de manifestarem uma preocupação de ordem instrumental quanto à alfabetização e aprendizagem deste público, destacam, por exemplo, a 
necessidade de relacionamentos que evidenciem novas atitudes, procedimentos e posturas. Dentre estes,

Os educadores devem estabelecer um relacionamento aberto e cordial com a família dos alunos para conhecer melhor suas necessidades, hábitos e comportamentos. Devem conversar naturalmente e esclarecer dúvidas ou responder perguntas dos colegas na sala de aula. Todos precisam criar o hábito de evitar a comunicação gestual e visual na interação com esses alunos. É recomendável também evitar a fragilização ou a superproteção e combater atitudes discriminatórias. (BRASIL. Ministério da Educação, 2007, p. 22)

As lacunas deixadas pelas orientações oficiais neste espaço de sete anos (20012007), revelam a ausência de aprofundamento numa parte que é fundamental, ao se considerar uma educação centrada na criança, a sua aprendizagem. Daí, surge a questão: quais estratégias podem nortear o fazer criativo do educador, deixando-se orientar pelo ato de aprender?

Sob o enfoque interventivo educacional no atendimento ao aluno com deficiência visual, Masini (1997) apresenta algumas orientações pedagógicas em consonância ao mundo circundante deste público da Educação Especial que assim seguem,

- Na comunicação, em nossa cultura, há predominância do visual e do verbal. Se o educador não estiver atento a isso, fará uso de conhecimentos não acessíveis ao deficiente visual, fazendo com que ele desenvolva uma linguagem e uma aprendizagem conduzidas pelo visual. Como os dados não provêm de sua experiência, não podem ser organizados por ele, verificando-se verbalismo e aprendizagem mecânica;

- Para que o deficiente visual organize o mundo ao seu redor, é necessário que use o mais possível todas as suas possibilidades (táteis, térmicas, olfativas, auditivas, cinestésicas), e fale sobre sua experiência perceptiva.

- A maneira de o deficiente visual relacionar-se com a professora é importante para que utilize e amplie suas possibilidades. A atitude da professora pode ser a de tutelar ou proteger (solicitude protetora ${ }^{3}$ ), dando-lhe informações diretivas sobre o que fazer, impedindo-o de explorar/conhecer e conhecer-se, ou ao contrário, a de estar junto a ele

\footnotetext{
${ }^{3}$ Cuidar de maneira envolvente e significante, "mimando" o outro, fazendo por ele, dominando-o e não propiciando oportunidades para que assuma os seus próprios caminhos. (MASINI, 2013, p. 136)
} 
(solicitude emancipatória ${ }^{4}$ ), contribuindo para que a pessoa deficiente visual encontre seus próprios meios de agir. (MASINI, 1997, p. 81-82)

Masini noutro texto (2007) pontua outros aspectos que merecem a atenção da escola e do educador nas relações de educabilidade, quais sejam:

- fazer contato por meio dos sentidos de que seu educando dispõe, manifestando consideração e evitando o sentimento de isolamento;

- mostrar expectativas que considerem suas possibilidades e limites ante a deficiência, em vez de expectativas cujos padrões de referência são os do desenvolvimento da criança vidente;

- estabelecer e esclarecer padrões apropriados de execução de atividades que a motivem a ajustar-se a suas possibilidades e seus limites;

- estar atento (a) à reação emocional de aceitação à deficiência visual e aos limites impostos por ela, atribuindo à pessoa com deficiência responsabilidades, de acordo com sua idade e desenvolvimento;

- propiciar oportunidades para falar de suas descobertas sobre as pessoas e objetos e de suas experiências perceptivas. (MASINI, 2007, p. 32-33)

Trata-se de intervenções pautadas pela autenticidade do educador que possibilita condições para o desenvolvimento humano dos alunos com deficiência visual, que solicitam uma aprendizagem orientada pelo redimensionamento dos procedimentos educacionais na ampliação da percepção docente daquilo que se manifesta na interação com o aluno em um determinado contexto social.

E mais, de acordo com Masini (1997, p. 83), "o educador pode ser criativo, buscando caminhos perceptuais". Uma empreitada que exige "engenho, paciência e energia". A criança deficiente visual "tem mais semelhanças do que diferenças com a criança que não tem deficiência visual. Elas têm as mesmas necessidades básicas físicas, emocionais e intelectuais" (MASINI, 2013, p. 36). Neste sentido, da atenção dada pelo educador na relação estabelecida com o aluno, o professor na situação de aprendizagem pode buscar em cada situação: “pontos de similitude referentes às necessidades básicas, ao que a criança manifesta e estabelecer níveis realísticos de expectativas para a criança, quer na escola, quer no lar”. (MASINI, 2013, p. 36). O olhar atento para aquilo que é

\footnotetext{
${ }^{4}$ Cuidar autêntico, de maneira envolvente e significativa, para que o outro assuma seus próprios caminhos, cresça e amadureça. (Idem)
} 
próprio do mundo da pessoa com deficiência visual, enquanto ação educativa dos educadores em geral, solicita de quem o faça, capacidade para:

Organizar e transmitir com clareza seu pensamento e de transformar condições insatisfatórias, contribuindo para que o aluno desenvolva confiança em si mesmo: na sua própria capacidade de realizar uma aprendizagem significativa, elaborando informações e apontando soluções criativas para situações de vida. (MASINI, 2013, p. 37)

Retomando o cenário das políticas de formação de professores, em 2011 ocorre a implementação do Programa de Formação Continuada de Professores em Educação Especial, e com o apoio especifico dos CAPs (Centro de Apoio para Atendimento às Pessoas com Deficiência Visual), que tem por objetivo, de acordo com a Secretaria de Educação Continuada, Alfabetização, Diversidade e Inclusão - SECADI, "apoiar a formação continuada de professores para o atendimento educacional especializado e a produção de material didático acessível aos estudantes com deficiência visual” (BRASIL. Presidência da República, 2016a) $)^{5}$. E oferece, também, formação continuada de professores para atuar nas salas de recursos multifuncionais e em classes comuns do ensino regular, em parceria com Instituições Públicas de Educação Superior.

A exequibilidade da estratégia 4.13 é engendrada por meio da Universidade Aberta do Brasil - UAB com a oferta de "cursos no nível de aperfeiçoamento e especialização na modalidade a distância, e presencial e semipresencial pela Rede Nacional de Formação Continuada de Professores na Educação Básica - RENAFOR" (BRASIL. Presidência da República, 2016b).

Hoje, de acordo com o Censo Escolar (BRASIL. Presidência da República, 2016c), o quadro de professores com formação em Educação Especial, apresenta os seguintes indicadores.

\footnotetext{
${ }^{5}$ Para maiores informações consultar os Programas e Ações do SECADI, Diretoria de Políticas de Educação Especial - DPEE, Centro de Formação e Recursos na homepage do MEC: http://portal.mec.gov.br/
} 
Gráfico 1 - Indicador de docentes com formação em Educação Especial

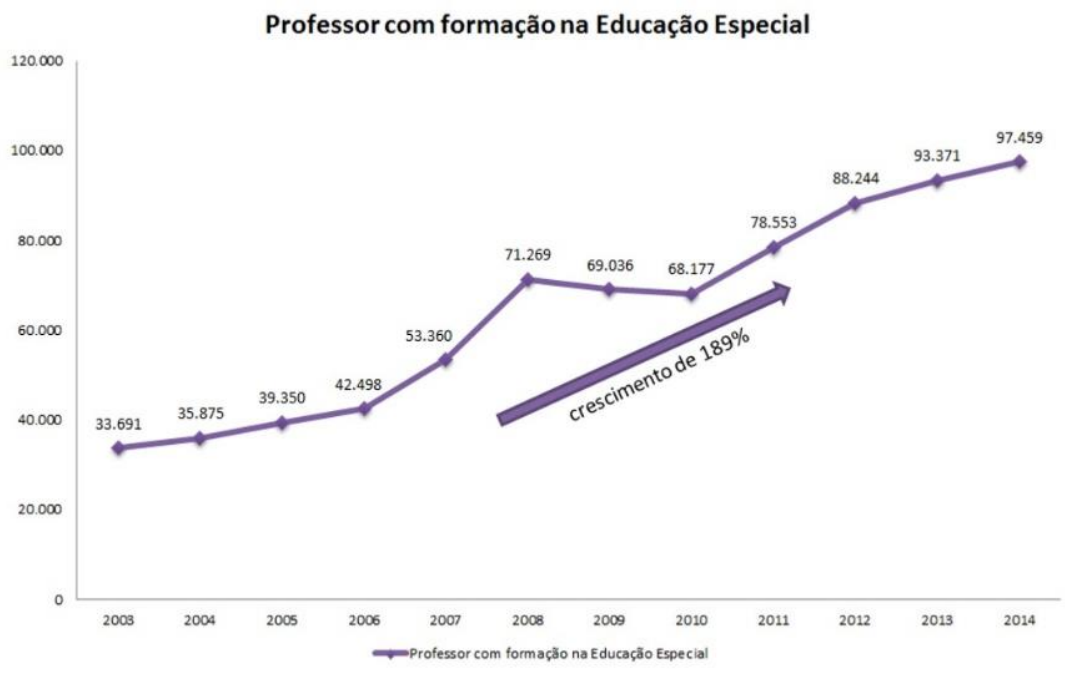

Fonte: MEC/INEP/DEED/Censo Escolar.

O gráfico acima revela um crescimento de $189 \%$ no período de 2003-2014, totalizando de 97.459 professores. O número de funções docentes que lecionam em turmas de Atendimento Educacional Especializado na Educação Básica vem crescendo desde 2009, alcançando a marca de 37.474 em 2014, conforme expresso no gráfico abaixo.

Gráfico 2 - Indicador de funções docentes no AEE

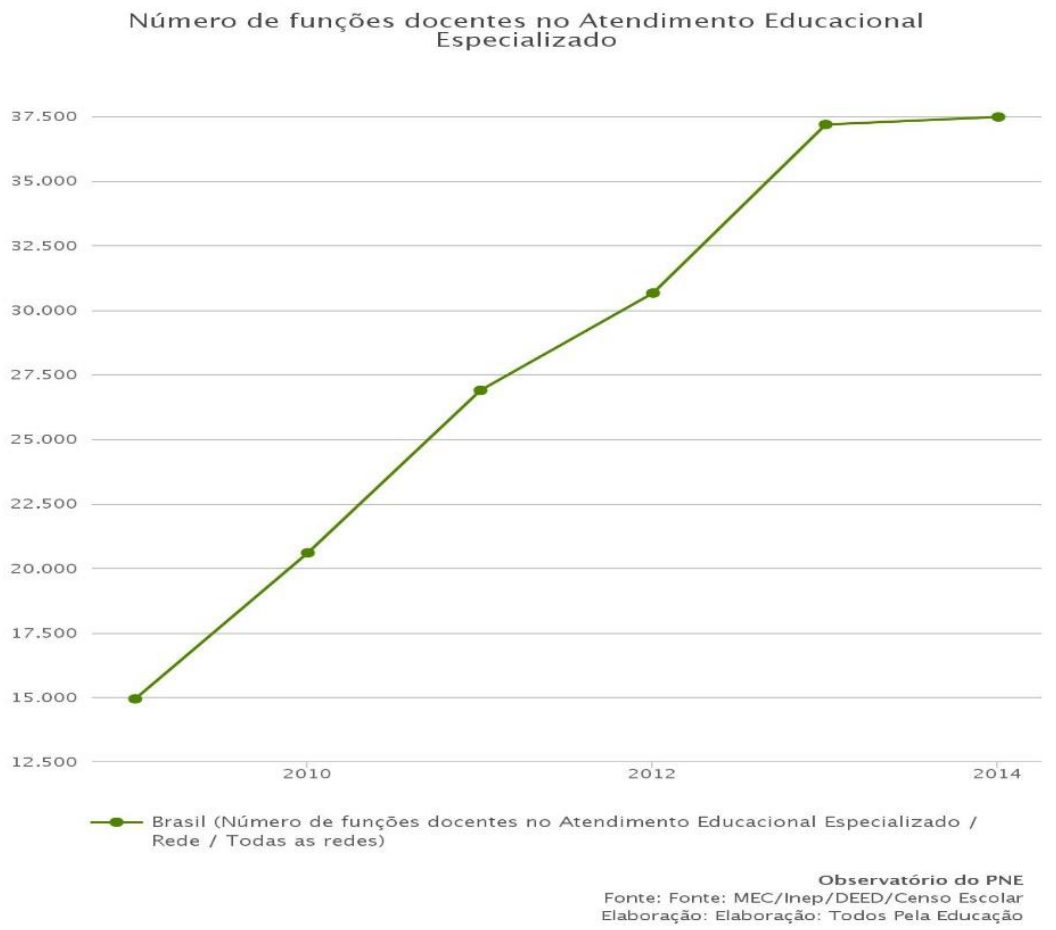


Os indicadores revelam que a estratégia 4.13 do PNE avança com os efeitos das políticas públicas de educação inclusiva na garantia de um sistema educacional inclusivo. Já a estratégia 4.16, que também é acompanhada pelo Observatório do PNE, está em andamento, uma vez que a Resolução CNE/CP $n^{\circ}$ 2, de 7 de julho de 2015, que define as Diretrizes Curriculares Nacionais para a formação inicial em nível superior e para a formação continuada estabelece que os cursos de formação inicial deverão prever, entre outros, conteúdos relacionados a Libras e à Educação Especial. Portanto, a inserção dos referenciais teóricos específicos é fundamental nos cursos de formação de professores para o atendimento do público da Educação Especial, visando assim, uma educação e desenvolvimento humano-significativos. Daí a relevância de operacionalizar esta estratégia, pois de acordo com o Observatório, "não há avaliação sistemática do que está hoje previsto nos currículos e da sua funcionalidade para preparar os professores para lidarem, na escola, com os efeitos das políticas de educação inclusiva" (OBSERVATÓRIO DO PLANO NACIONAL DE EDUCAÇÃO, 2016).

O retrato atual da situação da estratégia supracitada, não difere da estratégia 4.18, que também não tem uma avaliação sobre as perspectivas de desenvolvimento, bem como do status de implementação e indicadores da oferta efetiva de formação continuada por parte de instituições conveniadas.

Em síntese, as estratégias $(4.13,4.16$ e 4.18) que compõem a Meta 4 - Educação Especial/Educação Inclusiva, revelam a intenção de serem exequíveis "em razão das condições favoráveis criadas a partir da institucionalização da política de educação especial na perspectiva inclusiva, do financiamento da educação especial previsto no FUNDEB e das orientações pedagógicas disseminadas nos sistemas de ensino". (BRASIL. Ministério da Educação. Secretaria de Educação Especial, 2010, p. 26).

\section{Considerações finais}

O delineamento dos marcos históricos, das políticas públicas, e as orientações pedagógicas que convergiram para a discussão da Meta 4 do PNE tendo como eixo articulador a atual Política Nacional de Educação Especial preconiza que "para atuar na educação especial, o professor, deve ter como base da sua formação, inicial e continuada, 
conhecimentos gerais para o exercício docente e conhecimentos específicos da área". (BRASIL. Ministério da Educação. Secretaria de Educação Especial, 2008, p. 17). E mais,

Essa formação possibilita a sua atuação no atendimento educacional especializado, aprofunda o caráter interativo e interdisciplinar da atuação nas salas comuns do ensino regular, nas salas de recursos, nos centros de atendimento educacional especializado, nos núcleos de acessibilidade das instituições de educação superior, nas classes hospitalares e nos ambientes domiciliares, para a oferta dos serviços e recurso de educação especial. (BRASIL. Ministério da Educação. Secretaria de Educação Especial, 2008, p. 17)

Ao considerar a formação de professores como o ato de formar o docente, de educá-lo para o exercício futuro do magistério, Veiga (2012, p.15), afirma que este processo “envolve uma ação a ser desenvolvida com alguém que vai desempenhar a tarefa de educar, de ensinar, de aprender, de pesquisar e de avaliar”. E, para além disso, que a formação seja assumida como ato continuum, pois quando nos deparamos com a diversidade humana em sala de aula, muitas vezes não sabemos como agir e tratar "o diferente". Daí a importância das políticas públicas de Educação Continuada com programas e ações para formar professores para atuarem junto aos educandos público alvo da Educação Especial.

A educação, então, é chamada a tomar uma posição de parceria entre os entes federados com atitudes de corresponsabilidade, cooperação e participação com a implementação das políticas públicas intersetoriais de formação docente, que promovam a universalização do atendimento escolar aos estudantes com deficiência, transtornos globais do desenvolvimento e altas habilidades/superdotação.

As iniciativas oficiais ou de instituições particulares, que preocupadas com o atendimento educacional para o desenvolvimento humano, têm colaborado na educação do deficiente visual. Tudo isso, logrou desdobramentos para a formação e atuação docente imbricadas pelos aspectos históricos e políticos da Educação Especial.

Mas, todas essas recomendações legais e educacionais, revelam a necessidade constante de revisitar a realidade da educação brasileira, pois uma das dimensões da 
docência é a formação de professores, que "implica compreender a importância do papel da docência, propiciando uma profundidade científico-pedagógica que os capacite a enfrentar questões fundamentais da escola" (VEIGA, 2012, p. 14), de modo que avancem sob os efeitos das políticas de inclusão escolar no campo da Educação Especial, com horizontes de sentidos e significados para os cegos e pessoas com baixa visão.

\section{Referências}

BRASIL. Presidência da República. Lei 9.394: Lei de Diretrizes e Base da Educação Nacional - LBDEN. Brasília, 1996. Disponível em:

<https://www.planalto.gov.br/ccivil_03/Leis/L9394.htm>. Acesso em: 25 jul. 2016.

BRASIL. Presidência da República. Lei 10.172: Plano Nacional de Educação. Brasília, 2001. Disponível em: <http://www.planalto.gov.br/ccivil_03/leis/LEIS_2001/L10172.htm>. Acesso em: 25 jul. 2016.

BRASIL. Ministério da Educação. Plano de Desenvolvimento da Educação - PDE. Brasília: MEC, 2007.

BRASIL. Secretaria de Educação Especial e a Secretaria de Educação a Distância.

Atendimento Educacional Especializado Deficiência Visual: formação ccontinuada a distância de pprofessores para o aatendimento eeducacional especializado. Brasília: SEESP/SEED, 2007b.

BRASIL. Ministério da Educação. Inclusão. Revista da Educação Especial. Política Nacional de Educação Especial na Perspectiva da Educação Inclusiva. Secretaria de Educação Especial, v. 04. n 05. Brasília: SEESP, 2008.

BRASIL. Ministério da Educação. Secretaria de Educação Especial. Marcos Político-Legais da Educação Especial na Perspectiva da Educação Inclusiva. Brasília: Secretaria de Educação Especial, 2010.

BRASIL. Fórum Nacional da Educação. Plano Nacional de Educação (notas técnicas). Brasília: FNE, 2010. Disponível em: <http://fne.mec.gov.br/>. Acesso em: 2 de ago. 2016.

BRASIL. Presidência da República. Lei 12.796. Altera a Lei $n^{\circ}$ 9.394, de 20 de dezembro de 1996. Brasília, 2013a. Disponível em: <http://www.planalto.gov.br/ccivil_03/_ato20112014/2013/lei/l12796.htm>. Acesso em: 25 jul. 2016.

BRASIL. Presidência da República. Documento orientador programa implantação de salas de recursos multifuncionais. Brasília: SECADI, $2013 \mathrm{~b}$.

BRASIL. Presidência da República. Lei 13.005. Plano Nacional de Educação. Brasília, 2014. 
Disponível em: <https://www.planalto.gov.br/ccivil_03/_ato20112014/2014/lei/l13005.htm>. Acesso em: 25 jul. 2016.

BRASIL. Presidência da República. Programas e Ações: CAP - Centro de Apoio para Atendimento às Pessoas com Deficiência Visual. Brasília, 2016a. Disponível em: <http://portal.mec.gov.br/>. Acesso em: 1 de ago. 2016 a.

BRASIL. Presidência da República. Programa de Formação Continuada de Professores em Educação Especial. Brasília, 2016b. Disponível em: <http://portal.mec.gov.br/>. Acesso em: 1 de ago. 2016b.

BRASIL. Presidência da República. Principais Indicadores da Educação de Pessoas com Deficiência. Censo MEC/INEP. Brasília, 2016c. Disponível em:

<http://portal.mec.gov.br/secretaria-de-educacao-continuada-alfabetizacao-diversidade-einclusao/programas-e-acoes $>$. Acesso em: 1 de ago. 2016c.

BRUNO, Marilada Moraes Garcia; MOTA, Maria Glória Batista da. Programa de Capacitação de Recursos Humanos do Ensino Fundamental: deficiência visual vol. 1 fascículos I - II - III. Rio de Janeiro: Instituto Benjamin Constant: Rio de Janeiro. Ministério da Educação, Secretaria de Educação Especial: Brasília,/2001. (Série Atualidades Pedagógicas; 6).

CAIADO, Kátia Regina Moreno. Aluno deficiente visual na escola: lembranças e depoimentos. Campinas: Autores associados: PUC, 2003.

CARVALHO, Rosita Edler. A nova LDB e a educação especial. 3. ed. Rio de Janeiro: WVA, 2002.

FILHO, Adilson Vaz Cabral FERREIRA, Gildete. Movimentos sociais e o protagonismo das pessoas com deficiência. Revista Ser Social, Brasília: Programa de Pós-Graduação em Política Social-UNB. v. 15, n. 32. 2013.

FUNDAÇÃO DORINA NOWILL PARA CEGOS. [https://www.fundacaodorina.org.br/] São Paulo, 2016. Disponível em: <http://www.fundacaodorina.org.br/o-que-fazemos/servicosespecializados/\#programa-reabilitacao>. Acesso: 16 de jun. 2016.

MACHADO. Adriana Marcondes. et al. (Org.). Psicologia e direitos humanos: educação inclusiva, direitos humanos na escola. São Paulo: Casa do Psicólogo: Brasília: Conselho Federal de Psicologia, 2005.

MAZZOTTA, Marcos José. Inclusão e integração ou chaves da vida humana. São Paulo: 2001a. Disponível em: <www.educacaoonline.pro.br>. Acesso em: 15 de jun. 2016.

MAZZOTTA, Marcos José. Educação especial no Brasil: história e políticas. São Paulo: Cortez, 2001b.

MASINI, Elcie Fortes Salzano. O perceber e o relacionar-se do deficiente visual: orientando professores especializados. Brasília: CORDE, 1994. 
MASINI, Elcie Fortes Salzano. Intervenção educacional junto à pessoa com deficiência visual. In. BECKER, Elizabeth. Deficiência: alternativas de intervenção. São Paulo: Casa do Psicólogo, 1997.

MASINI, Elcie Fortes Salzano. A pessoa com deficiência visual: um livro para educadores. São Paulo: Vetor, 2007b.

MASINI. Elcie Fortes Salzano. 0 perceber de quem está na escola sem dispor da visão. São Paulo: Cortez, 2013.

OBSERVATÓRIO DO PLANO NACIONAL DE EDUCAÇÃO.

<http://www.observatoriodopne.org.br/>. São Paulo, 2016. Disponível em:

<http://www.observatoriodopne.org.br/>. Acesso em: 2 de ago. 2016.

SASSAKI, Romeu Kazumi. Inclusão: construindo uma sociedade para todos. 5. ed. Rio de Janeiro: WVA, 2003.

SOARES, Maria Aparecida Leite. CARVALHO, Maria de Fátima. O professor e o aluno com deficiência. São Paulo: Cortez, 2012.

VEIGA, Ilma Passos Alencastro. Docência como atividade profissional. In: VEIGA, Ilma Passos Alencastro; D’ÁVILA, Cristina (Orgs). Profissão docente: novos sentidos: novas perspectivas. $2^{\text {a }}$ ed. Campinas: Papirus, 2012.

VIGOTSKI, Lev Semionovitch. Fundamentos de defectologia: Obras Completas. Habana. Editorial Pueblo e Educacion, t. 5, 1997.

VIGOTSKI, Lev Semionovitch. A defectologia e o estudo do desenvolvimento e da educação da criança anormal. Tradução Denise Regina Sales, Marta Kokl de Oliveira e Priscila Nascimento Marques. Educação e Pesquisa. v. 37, n. 4, p. 861-870, dez. 2011. 